
Hinter dem Sachregister befindet sich ein ausführliches Verzeichnis der

\section{Guttentagschen Sammlung} Deutscher Reichsund Preußischer Gesetze

Textausgaben mit Anmerkungen Taschenformat

die alle wichtigeren Gesetze in unbedingt zuverlässigem Abdruck und mit mustergültiger Erläuterung wiedergibt 
Outtentagi

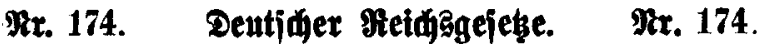

Textauĝgaben mit 2rnmertungen uno Sachregifter.

\section{Internationale Gchiedsplprechung}

Eine Sammlung oer fur sas Deutfige Reith verbinstichen

Verträge und Wertragóbejtimmungen,

Sie fich auf internationale serichtobarfeit,

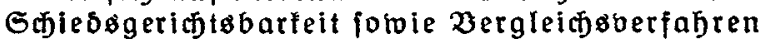
bezieben, nebit den dazugebörigen

\section{Seutichen Regierungsdenfichriften.}

Şerausgegeben und eingeleitet oon

\section{Dr. Serbert Fraus}

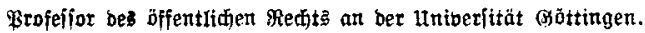

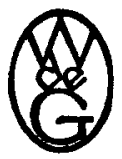

Berlin und Leipzig 1929.

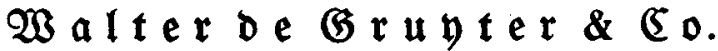

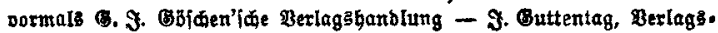

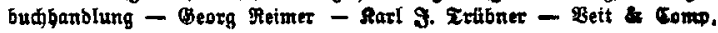


